\title{
The event experiences of attendees with food allergies, intolerances and coeliac disease: Risk loaded value-creation/destruction
}

\author{
Lina Weber \\ Oxford Brookes University \\ Peter Lugosi \\ Oxford Brookes University \\ plugosi@brookes.ac.uk
}

\begin{abstract}
Published as: Weber, L. and Lugosi, P. (2021). The event experiences of attendees with food allergies, intolerances and coeliac disease: Risk loaded value-creation/destruction. International Journal of Event and Festival Management. DOI: 10.1108/IJEFM-11-20200066. Please consult the published version if citing.
\end{abstract}

\begin{abstract}
Purpose

For attendees with allergies, intolerances and coeliac disease, accessing safe, nutritious and good quality food and drink is a vital but challenging dimension of events. This study sought to capture and analyse the lived event experiences of individuals with a variety of food-related health, wellbeing and safety needs.
\end{abstract}

\section{Design/methodology/approach}

This study adopted an inductive approach, using semi-structured interviews to gather qualitative data from participants with various food allergies and intolerances, or coeliac disease.

\section{Findings}

Attendees had low expectations regarding food choice, quality and value, which stemmed from past event experiences. Poor information about suitable food and drink, coupled with frontline staffs' perceived knowledge, responsiveness and care were frequently seen as sources of service failures. The data stress how exposure to potentially harmful foods and food avoidance influenced attendees' experiences. The findings also help to appreciate consumers' agency, identifying various coping strategies used by affected individuals to anticipate risks, engage in compensatory behaviours and mitigate the effects of unsuitable food and drink. 


\section{Originality}

This study is unique in examining the event experiences of individuals with food allergies, intolerances and coeliac disease. It demonstrates how practices in the crucial domain of food and drink provision can affect the overall event experience, with potential consequences at, across and potentially beyond the venue and occasion. From a theoretical perspective, the study conceptualises intersections of risk, value-creation/destruction and experiential consumption. It shows the 'episodic' and 'perpetual' impacts of 'risk loaded' consumption, while arguing that diverse value-creation/destruction practices mediate pathways leading to different experiential outcomes.

Keywords: Coeliac disease; Consumer experience; Eating out; Event catering; Food allergy; Food intolerance

\section{Introduction}

The impacts of food intolerances and allergies vary from mild discomfort to life-threatening symptoms such as anaphylactic shocks, while the autoimmune condition coeliac disease can also cause serious, long-term health problems (Ortolani and Pastorello, 2006; Turnbull et al., 2015). Physiological responses can start within minutes following ingestion, but symptoms can take several days to manifest (Putten et al., 2006; Turnbull et al., 2015). The most effective strategy to avoid symptoms is lifelong avoidance and elimination of the allergens from one's daily life (Putten et al., 2006; Sainsbury and Marques, 2018).

Food allergies have been reported to affect up to $10 \%$ of the population and global rates are increasing (Loh and Tang, 2018). Food intolerances, which covers a much wider set of symptoms and are more difficult to diagnose, have been estimated to affect $15-20 \%$ of the population (Lomer, 2015). Coeliac disease has been estimated to affect $1 \%$ of most populations (Lebwohl et al., 2018). Reported food sensitivities globally are rising, which is reflected in the growth of consumers demand and expanding products catering for diverse sub-segments over the past decade (IMARC Group, 2020).

Allergies, intolerances and coeliac disease, referred to hereafter in this paper using the cover term 'food sensitivities', can reduce quality of life and negatively affect individuals socially and psychologically (Nettleton et al., 2009; Sainsbury and Marques, 2018). Academics have explored food sensitivities as social phenomena (Rodriguez-Almagro et al., 2017; MacKenzie et al., 2010; Shah et al., 2014). Furthermore, a number of qualitative studies have examined the 
lived experiences of people living with these conditions (Olsson et al., 2009; King et al., 2019; Peniamina et al., 2014; Schiefert and Matteucci, 2018; Sverker et al., 2005, 2009). Many of these studies refer to dining out experiences more generally. However, research has paid insufficient attention to the experiences of those attending large, 'planned' events in dedicated venues, for example conferences, exhibitions and concerts.

For the purposes of this study, events are defined as planned, extraordinary phenomena, occurring at a given time and place, and involving socio-material practices (Getz and Page, 2016). Planned events share many of the characteristics of services: inseparability (they are produced and consumed simultaneously); variability (they are diverse, based on how they are provided, where, when and by whom); and perishability (they cannot be stored for later sale or use) (Reic, 2017). Foodservice offerings are often a crucial aspect of destination and event experiences (cf. Bezzola and Lugosi, 2018; Robinson and Clifford, 2012). Within an event context, the production and consumption of food and drink facilitates networking and sociality, satiated participants can enjoy the event and concentrate on its core functions, and the foodservice or hospitality offering can enhance the overall experiential proposition.

This study focused on dedicated venues, constructed for staging large-scale $(>2000$ attendees) events (Berners, 2019). Following Hassanien and Dale (2011), these are strategically designed venues that host events as their primary business activity, are located in a fixed place, and designed to include supporting services, including catering. Primary examples of this type of venue are concert and exhibition halls, stadia, arenas and conference centres. Limiting the sampling and analysis to these types of venues provided some level of empirical consistency, while enabling examination of the role of food provision and consumption within wider event experiences.

It is important to note that event experiences have dominantly been evaluated quantitatively (Armbrecht and Andersson, 2020; De Geus et al., 2016; Richards, 2020). Researchers have thus called for further studies of events using qualitative approaches that account for affective, subjective dimensions of perceptions and lived experiences (cf. Gellweiler et al., 2018; Holloway et al., 2010; Jackson et al., 2018; Ziakas and Boukas, 2014). This further reinforces the importance of examining the event experiences of consumers with specific dietary and foodrelated health requirements qualitatively. The study thus addresses two interrelated research questions:

RQ1. How do food-sensitive attendees experience events in dedicated venues, with specific reference to the role of foodservice products and services? 
RQ2. How do their specific dietary and health needs shape their expectations, behaviours and perceptions of their event experiences?

By adopting an inductive qualitative approach, the current study contributes to existing knowledge of social experiences with food sensitivities in several ways. Firstly, it provides novel insights for social science, health and consumer behaviour researchers into the subjective, lived experiences of individuals with dietary restrictions, distinguishing between expectations, experiences and coping strategies specific to this domain of social and business activity. Secondly, it provides insights for practitioners involved in events planning, marketing and operation, including and especially those involved in food and drink provision. It thus helps to sensitise practitioners regarding how food provision, information management and the training of frontline staff help reduce risk and create mutual value, which helps to build positive affective relationships between event operators and attendees with food sensitivities. Finally, from a theoretical perspective, the study conceptualises intersections of risk, valuecreation/destruction and experiential consumption. It shows the 'episodic' and 'perpetual' impacts of 'risk loaded' consumption, while arguing that diverse value-creation/destruction practices mediate pathways leading to different experiential outcomes. These theoretical insights offer transferable sensitising concepts for future research on consumption experiences and experience management involving segments with distinct needs and vulnerabilities.

\section{Literature Review}

\section{Social experiences with food sensitivities}

Food-sensitive consumers may experience a form of vulnerability because they feel exposed to a dependence on external factors and lack control over society's response to their condition (Bascuñán et al., 2017; Lee and Newman, 2003; Peniamina et al. 2014; Rodriguez-Almagro et al., 2017). Individuals following restrictive diets have been found to express significant concern about the impacts on their social life, as physical reactions in public places are associated with discomfort and embarrassment (Sverker et al., 2009). Studies conducted by Whitaker et al. (2009) and Skjerning et al. (2017) revealed that $32 \%$ of their sample were dissatisfied or very dissatisfied with their social life and $36 \%$ reported reduced social activity. The experience of being different from family and friends constrains social life, often shifting the focus from positive interaction to feelings of constant anxiety (Sverker et al., 2009). Individuals avoiding 
foods have reported convincing themselves that going out for events was not essential because they anticipated negative experiences (Sverker et al., 2009).

The feeling of being misunderstood and socially excluded at social gatherings has left individuals feeling that their sensitivities have diminished their quality of life (Whitaker et al., 2009; Jacobsson et al., 2012; Skjerning et al., 2017). Past research demonstrated how people with restrictive diets experienced feelings of shame and anxiety, which could be driven by fear that their needs would be forgotten or due to feeling excluded from full, uninhibited participation in social activities (Jacobsson et al., 2012; Olsson et al., 2009; Sverker et al., 2005; Zarkadas et al., 2013). Further concerns affecting the social life of food avoiding individuals include the feeling of being a nuisance, lack of empathetic companionship, and receiving unwanted attention (Crocker et al., 2018). Interestingly, research conducted by RodriguezAlmagro et al. (2017) revealed that perceived rejection and lack of support was most commonly found in hotels and restaurants, which reinforces the need to study social experiences of eating out in events.

\section{Social experiences of eating out}

Social gatherings have been identified as problematic for food-sensitive consumers, and difficulties in finding suitable food may be amplified when eating out at restaurants and cafés (Rodriguez-Almagro et al., 2017; Peniamina et al., 2014). Simpson et al. (2011) reported that $80 \%$ of their sample with coeliac disease avoided places that did not serve safe gluten-free food. $26 \%$ of the respondents in Lee and Newman's (2003) work stated that they violated their health needs when eating at restaurants and $21 \%$ breached their diet at parties and social functions (see also Olsson et al., 2009). This may occur because individuals try to avoid the shame and isolation of being unable to consume the same food as others; they do not wish to be a nuisance, feel uncomfortable refusing food, and also because potentially harmful ingredients are often hidden in processed foods (Bascuñán et al., 2017; Crocker et al., 2018; Sverker et al., 2005).

Individuals with restrictive diets have expressed concern about being unable to determine whether food contains harmful ingredients, and thus to fully assess the risks, because of inadequate allergen information or blanket 'may contain' warnings (Peniamina et al., 2014; Skjerning et al., 2017). The lack of available foods, or increased risk of contamination, can result in individuals bringing their own food, and engaging in advanced research and planning, thus feeling a loss of spontaneity in social consumption (Jacobsson et al., 2012; Crocker et al., 2018). 
In sum, researchers have identified challenges faced by individuals with food sensitivities, and recognised how these influence social experiences of eating out in general. However, despite the social and economic prominence of planned events, research has not sought to examine attendees' lived experiences, including the challenges they experienced and their responses. This study seeks to fill this substantial gap in current knowledge.

\section{Conceptualising event experiences}

Events experiences are conceived here as embodied and thus sensed or perceived as much as they are performed in (and in relation to) the event context, and where seemingly rational, cognitive information processing coexists with affective, subjective sensations (cf. Davies and Jaimangal-Jones, 2020; Lugosi et al., 2020b; Ziakas and Boukas, 2013). Foregrounding embodiment and performativity helps to stress that the body is key to the consumption experience, partly as individuals physically engage with the social and material-technological event environment, but also because consumers enact or co-create event experiences through verbal and physical actions.

Event experiences emerge over time, through a sequence of activities, with affective, cognitive and behavioural dimensions operating in and across multiple stages (Berridge, 2007; Morgan, 2008). Events involve desire, anticipation, risk assessment and preparation prior to attendance. Experiences are created through various socio-material service interactions in-situ. Furthermore, they extend beyond the actual event as consumers asses and represent their experiences (visually and textually), and prepare for future ones. Experiential value is potentially co-created during and across each of the event experience stages as different actors mobilise and align their operant resources (Lugosi et al., 2020b; Rust, 2020; Werner et al. 2019). However, where such resources are deficient or pursuing incompatible goals, actions at different stages of event experiences could also prompt value co-destruction.

Food sensitivities can be viewed as distinct forms of 'intrapersonal leisure constraint' within event experiences shaping preferences and participation. In conceptualising leisure constraints, Crawford et al. (1991) foregrounded psychological states and attributes, however, it is important to recognise the corporeal dimensions of consumption, particularly for those with food sensitivities. In sum, there are physical, psychological and social risks stemming from these types of intrapersonal constraint. Arguably, these can be sources of value co-creation or co-destruction within event experiences. The minimization of potential harm, or negation of consequences, by event organisers or attendees, can support immersive and constructive event experiences. In contrast, increased exposure to food-related risks may undermine engagement, 
leading to dissatisfaction. This study thus examines how such constraints are entangled in value co-creation and co-destruction in event experiences.

\section{Methodology}

\section{Research approach, sampling and recruitment}

Given the limited work in this area, the study adopted an inductive, qualitative approach, using semi-structured interviews to capture and understand individuals' experiences, perceptions and practices. Similar to other studies of experiential consumption (e.g. Lugosi, 2020b; Rust, 2020), the study used purposive, criterion sampling to recruit participants with diverse personal experiences, who could provide data rich insights that directly addressed the study's research questions (Patton, 2014). All participants were aged 18 or over, and essential inclusion criteria were that they had: a) a food intolerance, allergy or coeliac disease; and b) attended a large event ( $>2,000$ attendees) at a 'dedicated', permanent venue in the last 18 months. These venues included sporting stadia, theatres, and convention centres (e.g. Wembley Stadium and ExCel London). Example venues were included in the recruitment advert to ensure some level of consistency in participants' experiences. Temporary events and venues were excluded because they potentially reflected an eclectic range of event experiences and did not guarantee the same level of foodservice facilities.

The initial aim was to recruit through social media groups dedicated to food-sensitivities. The owners and moderators of four popular social media groups were contacted using the respective technology platform's direct messaging services to explain the study's purpose and to seek permission to post to the group. However, no response was received from the moderators. Consequently, an invitation was posted to one of the first author's non-specialist social media networks. The network's membership was not limited to those with allergies, intolerances or coeliac disease; nor was it geographically restricted. The open invitation contained information about the study's scope and focus, the inclusion criteria, expectations regarding participation and one of the researcher's contact details. Potential participants then contacted the researcher to volunteer their contribution, and arrangements were made to document ethical consent and conduct the interviews.

The final sample comprised 22 people: 3 with coeliac disease, 13 with intolerances (gluten, lactose, egg and fructose), 5 with allergies (wheat, legumes, dairy, egg, banana, nut, peanuts, fish and peas), and 1 person with an intolerance and an allergy (see Table I). The sample included 15 females and 7 males; the majority of participants were aged 18-27. Nationality and 
cultural heritage were not sampling criteria and the study was not comparative, but the sample included individuals from the United Kingdom (11), Germany (6), Netherlands (2), Canada (1), Spain (1) and the Czech Republic (1), which extended the possibility to capture diverse experiences. This sample size was used because analysis began during data collection, and by the 19th interview, it was increasingly felt that participants were repeating earlier insights. Nevertheless, three more were conducted to assure that saturation had been reached.

Table 1: Sample details

\begin{tabular}{|c|c|c|c|c|c|}
\hline Participant & Name & Gender & Age & Type of event visited & Food allergy/intolerance \\
\hline 1 & Abigail & $\mathrm{F}$ & $18-27$ & $\begin{array}{l}\text { Music Festivals, Theatre, Art } \\
\text { Events }\end{array}$ & Coeliac Disease \\
\hline 2 & Sonja & $\mathrm{F}$ & $48-57$ & $\begin{array}{l}\text { Theatre, Concerts, Sport } \\
\text { Events }\end{array}$ & $\begin{array}{l}\text { Lactose, Fructose and } \\
\text { Gluten Intolerance }\end{array}$ \\
\hline 3 & Aimee & $\mathrm{F}$ & $28-37$ & $\begin{array}{l}\text { Weddings and Celebratory } \\
\text { Events }\end{array}$ & $\begin{array}{l}\text { Lactose Intolerance and } \\
\text { Wheat Allergy }\end{array}$ \\
\hline 4 & Mark & $\bar{M}$ & $18-27$ & $\begin{array}{l}\text { Music Festivals, Conferences, } \\
\text { Meet and Greets, Hackathons }\end{array}$ & $\begin{array}{l}\text { Lactose and Gluten } \\
\text { Intolerance }\end{array}$ \\
\hline 5 & Sebastian & $\mathrm{M}$ & $48-57$ & Music Festivals & Lactose Intolerance \\
\hline 6 & Stephanie & $\mathrm{F}$ & $18-27$ & $\begin{array}{l}\text { Music Festivals, Concerts, } \\
\text { Job Fair, Football Games }\end{array}$ & $\begin{array}{l}\text { Fructose and Gluten } \\
\text { Intolerance }\end{array}$ \\
\hline 7 & Maria & $\mathrm{F}$ & $18-27$ & $\begin{array}{l}\text { Music Festivals, Conferences, } \\
\text { Theatre, Sporting Events }\end{array}$ & $\begin{array}{l}\text { Lactose, Fructose and } \\
\text { Gluten Intolerance }\end{array}$ \\
\hline 8 & Brian & $\mathrm{M}$ & $18-27$ & $\begin{array}{l}\text { Music Concerts, Comic Con, } \\
\text { Fan Expo }\end{array}$ & Coeliac Disease \\
\hline 9 & Lucy & $\mathrm{F}$ & $28-37$ & Conferences & Lactose Intolerance \\
\hline 10 & Paul & $\bar{M}$ & $58+$ & Football Games, Conferences & Gluten Intolerance \\
\hline 11 & Anne & $\mathrm{F}$ & $48-57$ & $\begin{array}{l}\text { Music Concerts, Football } \\
\text { Games, Tennis Matches, } \\
\text { Theatre }\end{array}$ & Lactose Intolerance \\
\hline 12 & Benjamin & $\mathrm{M}$ & $18-27$ & $\begin{array}{l}\text { Football Games, Music } \\
\text { Concert }\end{array}$ & Legumes family Allergy \\
\hline 13 & Klara & $\mathrm{F}$ & $18-27$ & $\begin{array}{l}\text { Football Games, University } \\
\text { Ball }\end{array}$ & $\begin{array}{l}\text { Lactose, Egg and Gluten } \\
\text { Intolerance }\end{array}$ \\
\hline 14 & Laura & $\mathrm{F}$ & $18-27$ & $\begin{array}{l}\text { Music Festivals, Food } \\
\text { Festivals, Theatre, Football } \\
\text { Matches }\end{array}$ & Lactose Intolerance \\
\hline 15 & Rosa & $\mathrm{F}$ & $18-27$ & $\begin{array}{l}\text { University Events, Music } \\
\text { Concerts, Conferences }\end{array}$ & Lactose Intolerance \\
\hline 16 & Emily & $\mathrm{F}$ & $18-27$ & Music Concerts & Coeliac Disease \\
\hline 17 & George & $\bar{M}$ & $18-27$ & $\begin{array}{l}\text { Award Ceremonies and Drink } \\
\text { Receptions }\end{array}$ & $\begin{array}{l}\text { Dairy, Egg and Nut } \\
\text { Allergy }\end{array}$ \\
\hline 18 & Phillip & $\mathrm{M}$ & $18-27$ & $\begin{array}{l}\text { Music Concerts, National and } \\
\text { International Scouting Events }\end{array}$ & $\begin{array}{l}\text { Peanut and Legumes } \\
\text { family Allergy }\end{array}$ \\
\hline 19 & Olivia & $\mathrm{F}$ & $18-27$ & $\begin{array}{l}\text { Music Concerts and Food } \\
\text { festivals }\end{array}$ & Peanut Allergy \\
\hline
\end{tabular}




\begin{tabular}{|llllll|}
\hline 20 & Susan & F & $48-57$ & Theatre, Work Events & $\begin{array}{l}\text { Egg, Fish, Nut, Peas, } \\
\text { Banana and Dairy } \\
\text { Allergy }\end{array}$ \\
\hline 21 & Katerina & F & $18-27$ & Music Concerts & Gluten Intolerance \\
\hline 22 & Chloe & F & $18-27$ & Music Concerts, Theatre & Gluten Intolerance \\
\hline
\end{tabular}

\section{Data collection}

The interviews sought to make participants comfortable and encourage them to tell their stories with limited interference from the interviewer. Initial exploratory questions prompted participants to talk about themselves, their ailments and general events experiences. Specifically, the interviewer opened the conversations by asking: 'Please tell me about the sort of events that you like to attend.'; 'What type of events have you visited in the last 18 months?'; and 'Can you tell me about your [condition] and how long you have been living with this [condition]?'.

Subsequent open questions elicited descriptive narratives regarding event experiences and practices. For instance: 'Can you tell me about a particularly positive food-related experience that you have had in an event venue?' and 'Can you tell me about a negative experience in an event venue that you have had involving your [condition]?'. The interviews also used focused contrast questions as an alternative strategy to help identify particular features, incidents or issues that informed their attitudes and expectations; for example: 'Are there any types of events that you would avoid due to the limited dietary offerings?'. Core questions were accompanied by elaborative probes asking them to explain their answers, and to describe what happened, what they did in situations and how they felt, which helped to capture their perceptions, emotions and behaviours.

Depending on the participant's preference, interviews were conducted via Skype, Facebook, Facetime or WhatsApp call. This provided opportunities to interview individuals in different countries and increased researcher safety. One interviewee opted for an e-mail interview, which came with the advantage that the written text was immediately ready for analysis. There was opportunity to ask follow-up questions via e-mail, but the written responses provided rich and relevant data without requiring prompts to elaborate, and so the data were used in the final analysis. The interviews were conducted in English, lasting between 30-60 minutes and recorded digitally to aid transcription. 


\section{Data analysis}

The interviews generated 91,532 words of transcribed text, which was analysed thematically (Saldaña, 2009). The interview schedule provided a broad sensitizing framework for the analysis, but the flexible, exploratory, semi-structured approach enabled the generation of new areas of discussion. Focused coding was therefore combined with open coding (ibid.). A noted above, analysis began during the data collection. Patterns in the data were identified and evaluated through active listening and note taking during interviews, (re)reading transcripts and repeated listening to recordings. A reduced data set comprising 36,632 words was preliminarily reordered under seven themes: expectations, experiences, coping practices, pricing, preparation and advice for attendees and organisers. However, this paper focuses on the three primary themes of expectations, experiences, and responses and coping mechanisms including those practiced before and during visits to venues. Nevertheless, the findings regarding responses and coping refer to implications that extend beyond the event.

\section{Findings and discussion}

\section{Event expectations}

Given the extraordinary nature of planned events, attendees are likely to have pre-visit expectations regarding service and value (Berridge, 2007), although proponents of experiential perspectives have recognised that these can be vague (Morgan, 2008). Significantly, among this cohort, food sensitivities played a substantial role in framing and thus mediating expectations regarding their event experiences. Participants generally had low expectations of food provision, encompassing the availability of food to suit their specific needs, its perceived quality and value. For example:

I usually expect there to be probably like one or two things on the menu. And I would actually say my expectations are pretty low in general. When I've been to the theatre, you know, there's really barely any options of any kind of food or even snacks that you can have.

(Emily, Coeliac disease)

Attendees' expectations were framed by their subjective assessments of risk underpinned by perpetual hazards of food availability. While risk taking can be viewed as a positive feature of experiential leisure consumption (Holm et al., 2017), food related risks were conceived as 
sources of dissatisfaction. This is significant because, for event attendees with food sensitivities, their experiential expectations were therefore negatively 'risk loaded' from the outset. Consequently, the potential for value co-destruction was embedded in the experiential propositions and the consumption experience. Arguably, the negative impacts were more pronounced for consumers with severe allergies, for whom the risks were immediate and potentially life-threatening. This was reflected in their awareness of hazards, and therefore of the potential for negative experiences. Their assessments of and preparedness for allergyrelated risks were more precise than those with relatively minor or delayed symptoms stemming from intolerances.

Even when specialist food was available, it was seen as overpriced. One interviewee believed that specialist products such as gluten free foods were 'in fashion at the moment', which for them explained why 'they [event or catering managers] just stick a few extra pounds on the price, just because of the demand.' Others expanded on this notion of overpriced specialist food at events, explaining how this influenced their overall experience:

If you can expect normal food to be around \$15, the gluten free variant at a big event is going to be like \$24 plus, which I do expect, but it's just, it's kind of insanity. And it definitely eats into how much I'm willing to spend at that event outside of that. It kind of depends on how desperate I am.

(Brian, Coeliac disease)

I think it's normal that it's more expensive. But that's because I know that lactose free milk is much more expensive than regular full milk. I don't think it should be more than 20\% extra though, so if it's above $20 \%$ more of the price, I would definitely not buy it. Between 0 and 20\%, I would be much more likely to buy it. (Anne, Lactose intolerance)

Poor expectations were based on past event experiences with limited choice and poor quality specialist dietary food. As one participant observed:

I think it can be quite sad sometimes, for example at a couple of conferences that I have been to, they had an amazing spread of food like cheese crackers and lots of really nice food and then the gluten free and dairy-free lunch is just sad in comparison and it tasted horrible. 
(Lucy, Lactose intolerance)

Previous work highlighted the importance of high-quality supporting services such as catering in creating lasting, positive impressions for new and existing event participants (Foroughi et al., 2014). Embedded disappointment and frustration meant that people with food sensitivities approached events with negatively weighted (risk loaded) expectations. Importantly, just as value-creation is often argued to be dependent on creating 'individualised' experiences i.e. those perceived subjectively to be preferable (Holbrook, 2006); for these consumers, value destruction was also individualised insofar as it affected them in unique ways, in contrast to the experiential value accessible to others without analogous needs.

\section{Experiences}

Arguably, food provision and consumption for attendees with sensitivities were primarily forms of 'pure risks', which only have the potential to do harm (Hopkin, 2018). However, it is also possible to view food and drink for those with health needs as sources of 'speculative' risks (ibid.), which could be used as a form of value-creation. Specifically, operators' willingness and ability to foreground the availability of specialist foods in pre-event marketing efforts offered ways to create unique, engaging experiential propositions for these segments.

Operators' attempts to reassure attendees prior to the event to build positive relationships could be amplified during event experiences by showing care and competence regarding specialist diets. For example:

I was inquiring about some of the food that was on offer, and they simply asked, would you like to see the allergen menu and they simply showed it to me. So you know, the ability to find out what ingredients are in food and the allergen menu having been readily available was great. Because they showed awareness of allergies.

(Phillip, Peanut and legume family allergy)

Some countries have well-established and legally enforced cultural awareness of food allergies and intolerances, which has translated into routinized and trusted procedures. However it is important to recognise that legal frameworks, enforcement and embedding of good foodservice practices are highly variable internationally (cf. Endres et al., 2021; McAdams et al., 2018; Wen and Kwon, 2019). The growing prevalence of food sensitivities, and the high 
profile cases of negative incidents reinforces the need invest in stronger foodservice practices (Soon, 2020). These encompass multiple operational domains including transparent menu labelling, improved procedures for food handling, preparation and service to reduce risks, and investment in training to improve risk-related knowledge and communication (Carter et al., 2020). Quotes such as that above reinforced the value-creation potential of embedding systems ensuring safety and transparency, which consequently engendered trust between consumers and event organisations. Positive experiences also pointed to affective dimensions of value-creation as people felt the organisation showed care towards them in accommodating their unique experiential needs. For example:

They were exceptional, as soon as I turned up to the event, they sought me out and double checked everything that they found for me and cooked in a separate area of the kitchen, so to avoid cross contamination. The best was that it was bought out at the same time as all the other attendee's food. And I think that's a thing I appreciate, when they don't make you stand out to all the other attendees. Usually they will clearly say to you on the low that they're doing lots of proactive steps to avoid or minimise any risk, but then when they bring dinner out, they sort of announce that you are the special person. And the event caterers at [the venue] didn't make a big fuss about it publicly, which is something I really appreciate. It does make an awful lot of difference to your experience.

(George, Dairy, egg and nut allergy)

This participant's reflection also stressed the importance of discretion. Past studies have highlighted the negative consequences of making dietary difference conspicuous (e.g. Olsson et al., 2009; Sverker et al., 2009). Wen et al. (2020) argued that service staff's knowledge and flexibility regarding food allergies shapes diners' satisfaction. Extending this, developing 'emotionally intelligent', personalised service practices that appreciate and reduce the stress caused by visibility can potentially enhance the value created through event experiences.

However, as expected, many of the participants recounted negative experiences and the prevalence for value destruction with extended impacts. For instance, because of being served unsuitable food, without adequate information, one of the interviewees stated 'I did not end up going to the event, because I had to go home and the whole day was ruined'. Another interviewee described a similar situation, which again showed the wider implications of poor food related practices coupled with inadequate information management regarding ingredients. 
I also had to suffer through a comedy show where the food that I had was not gluten free and I was getting sick right before a show that I paid hundreds of dollars for. I ended up going but I felt nauseous the entire time and didn't end up really enjoying my experience.

(Brian, Coeliac disease)

The physical symptoms of a broken diet could undermine the entire event:

I drank or ate something. And when I eat something that I'm intolerant to, I need to go to the toilet instantly. So yeah, so for at least, 10 to 20 minutes I was running around to find the toilets. As you know, event venues can be quite big. And then there was a queue and then I eventually I got to the toilet. And then I was just on there for like half an hour before feeling better again. And then yeah, at some point, I left the toilet and then I needed it again. I'm not going to lie, it kind of ruined my entire event experience.

(Laura, Lactose intolerance)

Previous studies of consumers with unique experiential needs have shown that failures in seemingly small domains of practice can influence the affective and behavioural dynamics of the broader consumption experience (Lugosi et al., 2016, 2020a). Similarly, in the context of the current study, exposure to food and drink related risks were highly likely to influence attendees' experiences in and across multiple domains of the event. The scope and intensity of those impacts depended on the type and severity of attendees' unique health needs or conditions. Conceptually, this helps to distinguish between risks that had what may be called 'episodic' impacts, creating harm and dissatisfaction in during specific moments, and risks with 'perpetual' impacts meaning they could generate dissatisfaction across the wider experience. Events take place over relatively short periods; they are 'moments of truth' where organisations' experiential propositions are reified, or collapse (Tum et al., 2006). Failure to meet expectations in the domain of food provision is highly likely to be assessed in terms of value-destruction, undermining consumers' relationship with the entire event, with limited opportunities to engage in service recovery (ibid.). Moreover, as Simpson et al. (2011) suggested, these types of negative experiences are likely to result in individuals avoiding events and venues that fail to meet their specific needs. 
The intersections of negative psychological and physical effects were also experienced when event participants resorted to food avoidance. A participant with coeliac disease explained 'if you are hungry at an event you will never be in a good mood and it's disappointing because you watch people eat and you just think great, I can't eat that.' Another contributor similarly noted that it was 'physically draining when attending long events with no food'. Similarly:

So I went to the food bar at [the venue] and asked if they had anything that I could have and the waiter just looked at me and said no, we don't do anything like that. And because there was such a long cue, I ended up just buying a small bag of crisps and ended up feeling starving for the duration of the event, which was 4 hours long. I felt like I was going to pass out.

(Maria, Lactose, fructose and gluten intolerance)

Peniamina et al. (2014) and Rodriguez-Almagro et al. (2017) highlighted the difficulties of finding suitable dietary foods when dining out more generally. However, this study's findings highlight the subjective, affective and physical implications of not being able to access adequate foods. Importantly, it stresses how poor performance in this particular domain of operations management can fundamentally disrupt the entire event experience, which has potential implications for the brand, word of mouth, and likelihood of return. Put another way, value codestruction was scalable.

In many incidents, the availability of information, coupled with staffs' perceived knowledge and responsiveness appeared to be important factors for managing risks. This reflects findings from other studies that showed how frontline staff's perceived knowledge and communication shaped customer satisfaction (Wen et al., 2020). Researchers have also recognised the importance of clear food allergen labelling for consumers and organisations, especially because of the severe consequences resulting from poor information management (Peniamina et al., 2014; Skjerning et al., 2017). Several interviewees stated that they had negative event experiences because they were 'unable to tell if the food was safe'. Moreover, an interviewee recalled becoming frustrated by the event personnel's response to an allergen query, which signalled inadequate professional knowledge by the frontline staff, poor management systems and a risk-averse attitude from the wider organisation: 
Like “we can't 100\% say yes or no" you find quite frustrating because I feel like they probably should be sure. People are so scared that they don't want to take any responsibility and it's easier for them to just put blanket statements on all food.

(Olivia, Peanut allergy)

Such frustrations regarding unclear information and generalised warning statements echo concerns identified in previous work (Peniamina et al., 2014). County or region-specific legislation may compel providers to provide clear information, but this type of legal mechanism may not be in place internationally, and even if present, may not translate into robust practices in event settings (cf. Endres et al., 2021; McAdams et al., 2018; Wen and Kwon, 2019). As Begen et al. (2018) observed, signalling the presence of risks communicates awareness, but it may merely convey minimum statutory compliance, which fails to instil trust and confidence in operators' capabilities.

Participants also highlighted that the lack of information was sometimes coupled with a lack of perceived empathy. Many interviewees became frustrated with events staff because they seemed unaware regarding food sensitivities and their consequences. As one participant recalled:

I even remember I was at the football match and asked the waitress Oh, do you maybe have any gluten free bread or dairy free milk and, I mean, it happens a lot. But then there's just the answer, like, what is gluten? Like, what is that? And no, we don't have that, I don't know what that is. Are you sure you don't want to just eat normal things? Like it's fine. We can just give you something normal. People kind of do that all the time.

(Klara, Lactose, egg and gluten intolerance)

The lack of responsiveness towards meeting consumers' needs or empathy regarding the consequences of disappointing the consumers represents multiple service failures. The cumulative effects of such service failures are likely to provoke negative affective responses leading to poor service evaluation and ultimately value-destruction (Harrison-Walker, 2019).

The frustrations caused by lack of choice, information and, perhaps most seriously, understanding, were compounded by procedures that prohibited event participants from bringing self-made food into venues. As one individual stated, the inability to bring your own safe provisions 'forces you not to eat and that really limits people who have no other option and 
have such specific allergies that they know they can't get catered food for.' Another participant recalled:

The point was that they (event staff) didn't accept my allergy pass and they only said that in general you're not allowed to bring food inside, but they were not thinking that there are some people who are not able to eat the normal food. They should be more sensitive towards things like this because I do not want to save money, I just want to be able to eat something at an event.

(Aimee, Lactose intolerance and wheat allergy)

These types of incidents reflected multiple procedural failures that intersected to frustrate attendees with food sensitivities. They restricted choice and undermined the embodied event experience. They also constrained opportunities for value-co-creation, where consumers could mobilise their own resources to compensate for limitations in the organisers' service capacities. In sum, multiple forms of value-destruction potentially undermined the affective relationships that consumers could build with event organisers, venues and their operators because those with special food requirements were uniquely affected by their actions.

\section{Reactions and coping practices}

As noted above, value co-destruction driven by food and drink provision was an individualised aspect of event experiences for attendees whose needs remained unmet. Interviewees often expressed a sense of exclusion. As one observed, event experiences left them feeling 'singled out, forgotten and just put to the side'. Expressed alternatively:

I think you always miss out ... you do sort of feel like you're not quite enjoying the event as much as everyone else. You can't just join in like the rest of society, so you watch others have fun.

(Aimee, Lactose intolerance and wheat allergy)

Participant assessed that they 'miss out on the social aspect of the events like talking about the food, so you always feel slightly segregated because you just can't experience the event in the same way'. This echoes findings from previous research that highlighted feelings of being misunderstood and socially excluded among people with food sensitivities, which affected their perceived quality of life (Jacobsson et al., 2012; Skjerning et al., 2017; Whitaker et al., 2009). 
Following Sverker et al. (2005), feelings of shame, anxiety and fraught stem from the underlying fear that the individual's needs are being forgotten and of feeling downgraded because of perceived exclusion from social activities.

Frustration, anger, disappointment and exclusion expressed by participants corresponded with findings of previous studies (Jacobsson et al., 2012; Zarkadas et al., 2013). Echoing Sverker et al. (2009), feeling different frequently shifted perceptions of the experience from pleasure to anxiety. Participants also pointed to wider negative psychological consequences, for example, worrying about 'looking like you aren't fun and not wanting to be a party pooper because you can't participate... which just diminishes your confidence'. Similarly, a participant observed 'I was very embarrassed and ashamed and I just really wanted to go home and felt really awkward because I couldn't talk about it [reaction to intolerance] openly'. Another interviewee suggested that negative event experiences amplified a wider sense of scepticism towards others and themselves:

You lose confidence, not just in the company, but you lose a bit of self-confidence as well. You begin to doubt the competency of the catering company because you just feel like you are not being taken seriously and then as a result of losing confidence in the company, you then lose confidence in yourselffor not being able to speak up and intervene.

(George, Dairy, egg and nut allergy)

Analogously, previous studies of parental experiences in public spaces suggested that negative in-venue encounters reinforced a wider sense of social exclusion and self-doubt that extended beyond the particular place or experience (Lugosi et al., 2016). These findings thus point to event operators' wider social responsibilities insofar as their domain-specific service failures have potentially far-reaching consequences for their consumers.

Importantly, the interviews helped to identify the role of consumer agency in managing food-related risks in events. Value was co-created as consumers anticipated risks and potential service failures, and consequently mobilised various resources in coping practices (cf. Lugosi et al., 2016, 2020a). Among the interviewees, the most common way to compensate for poor food was to self-cater: 'I usually will just bring like a container of food that I can eat so I don't need to worry about it... and know that I'm going to be $100 \%$ safe'. This strategy was especially important when visiting new venues and in situations where sufficient pre-visit information was unavailable: 
If I'm going on a longer conference for three or four days, I will take a food supply with me of both sweet and savoury. Because if I go to a place that I have not been before I don't know how well they will cater for me. I just make sure I've got something with me because again if you're there for a few days you know that just a cup of tea won't be enough.

(Paul, Gluten intolerance)

Other pre-visit coping practices included preloading: eating heavy meals as well as drinking large quantities of water prior to attending an event. Several interviewees stated that they drank lots of water prior to attending an event because they felt this helped their body break down and 'flush out' problematic ingredients. They believed that if they consumed 'more water than usual then maybe [the harmful food] goes through your body faster and it will have less of a reaction'.

Reflecting previous findings (see e.g. MacKenzie et al., 2010), in-situ coping practices sometimes involved breaking diets, at least in limited ways, although this was not possible for people with severe allergies.

I have broken my diet many times sadly. But even when I break it, I always make sure that I only have a little bit and would never eat a full pizza for example. Usually I would be at an event and would not eat anything, but if the event is very long then I usually give in after an hour or so just because I get so hungry and I am starving. (Sonia, Lactose, fructose and gluten, intolerance)

Another respondent similarly noted:

...if I do eat this, but only maybe three bites instead of the whole pizza, I'll have something to fill me up. Maybe that will upset my stomach but at least I know I won't spending the next 24 hours in the bathroom somewhere.

(Rosa, Lactose intolerance)

Other respondents resorted to coping mechanisms aimed at negating future consequences. For example, one peanut allergy sufferer often tried to capture proof of his allergic reactions to evidence the problem for organisers. 
I would obviously in the first moment get myself seen too, but at the same time, try and get one of my friends to either get pictures or to store away that product for closer examination later on. Because I very much want to return to the event manager to say hang on a minute, this is definitely not okay and here's a piece of proof. I'd be able to solve a dreadful situation in the future with the evidence at hand and try to confront someone.

(Phillip, Peanut and legumes family allergy)

This type of coping strategy could help to create diverse forms of value and different pathways to its co-creation. Specifically, following Schoefer and Ennew (2005), evidencing service failures could create individualised economic value in terms of perceived 'distributive' justice when consumers received financial compensation. Psychological value may have also been created as affected consumers experienced 'procedural' or 'interactive' justice in service recovery (ibid.). Recording failure could also be seen more altruistically in the creation of value for future use, especially if complaint behaviour drove service improvements for consumers with food sensitivities.

Where exposure to allergen-related risks could not be avoided, individuals' preparatory effort shifted to mitigating the negative outcomes. Mitigation could take psychological forms as affected individuals created mental defence strategies to cope with the stresses of potential exposure and improve resilience (MacKenzie et al., 2010). However, the data pointed to behavioural forms, which allowed patrons to continue engaging with the event rather than withdrawing or minimizing their participation As one individual explained, they always took Ibuprofen tablets to overnight events because 'if you take them early on then you can at least kind of get rid of the pain that comes with eating unsuitable food'. Similarly, another participant observed 'I would always make sure that I had my lactose pills with me and never go anywhere without them, especially if it's a food event.' As expected, individuals with severe food allergies were conditioned to prepare for worst-case scenarios: 'I also make sure I've got my EpiPen and histamine medicine with me ... I can't go anywhere without them'.

\section{Conclusion}

This study examined how attendees with various food allergies, intolerances and coeliac disease experienced events in dedicated venues, with specific reference to the role of foodservice products and services. Moreover, it questioned how dietary and health needs 
shaped consumers' expectations, behaviours and perceptions of their event experiences. The findings showed how food sensitivities manifested in and influenced multiple stages and dimensions of event experiences (see Figure 1 for a summary).

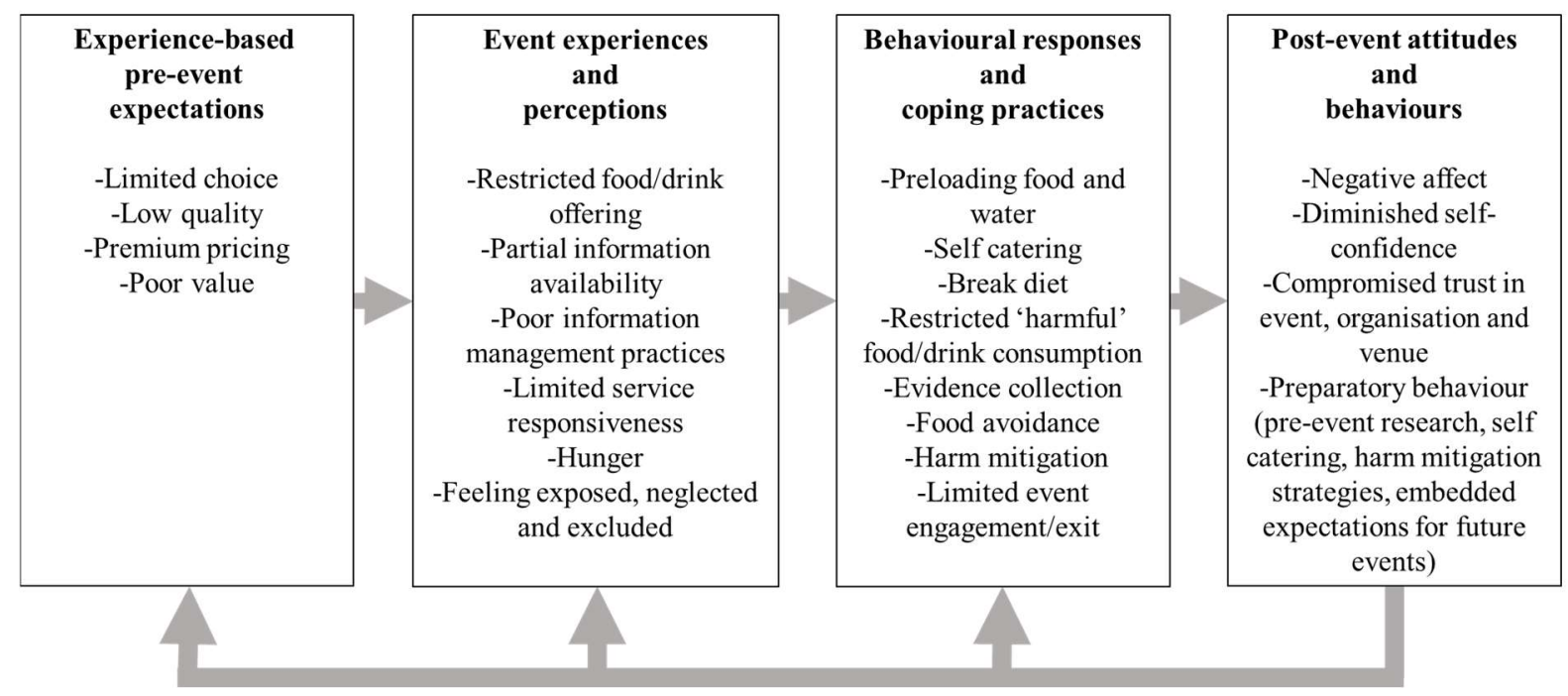

Figure 1: Event experiences and their consequences for attendees with food allergies, intolerances and coeliac disease

The data demonstrated that consumers often came with low expectations of venues regarding choice, information and value, which were developed through past event patronage. These were frequently reinforced by their experiences, and the lack of adequate food provision, information or perceived responsiveness by operators reinforced feelings of dissatisfaction. The findings showed how poor quality food provision could disrupt the overall event, thus creating pathways to value-destruction. Significantly, the data also pointed to avenues for valuecreation, highlighting the role of consumer agency, insofar as attendees prepared for negative event experiences and engaged in a series of coping behaviours to avoid harm or at least mitigate the consequences of poor food and drink provision.

\section{Implications for theory}

The findings help to conceptualise intersections of risk, value-creation/destruction and experiential outcomes. For vulnerable individuals, consumption scenarios can have what we have termed a 'risk loading' - the omnipresence of hazards - representing pure risks that are negatively weighted to disrupt or damage experiential outcomes. From a positivist perspective, such risk loadings can be viewed as antecedents to decision making, in-situ behaviour and post- 
consumption evaluation. From an interpretivist perspective, such risk loadings can be seen as 'framing devices', creating imperatives that shape sensemaking and embodied consumption practices (cf. Lugosi et al., 2016; 2020a). Importantly, the notion of risk loading can be integrated into theoretical models of experiential consumption to help conceptualise processes and outcomes for distinctive consumer segments according to their objective and subjective exposure to specific risks.

Linked to this, the findings were used to conceptually distinguish between 'episodic' and 'perpetual' impacts. The former had the potential to affect value-creation/destruction at specific moments; the latter had ongoing impacts that extended across and beyond the consumption experience. Stressing these interactions helps to theorise how value-creation/destruction practices e.g. in areas of knowledge management, communication, responsiveness, coping behaviours etc., among consumers and producers, may mediate or moderate the impacts of risk loadings on experiential outcomes. Conceptually, the potential application of these findings extend beyond food allergic or intolerant consumer segments and event contexts. They could be used to conceptualise and research the experiences of other vulnerable consumer groups, in different consumption settings.

\section{Implications for practice}

There is a global rise in food allergies, intolerances and coeliac disease, and their impacts on management often arise from negative incidents when individuals have been harmed due to service failures (Soon, 2020). This study has shown that their impacts on consumer experiences and experience management are negatively loaded. The findings stress the critical role of food and drink-related 'supporting' services in event planning and operations management. Practices in this relatively narrow but pervasive domain of activity have the potential to shape satisfaction regarding the wider experience. Therefore, it is reasonable to propose that positive and negative food related experiences are likely to shape consumers' affective relationships with and attitudes toward brands and venues, post-event word of mouth behaviours, and likelihood of repurchase.

The study's findings give impetus for event and foodservice operators to invest in process design and training across several areas. These encompass knowledge management, including how consumers' risks and needs are collected and utilised prior to attendance in responsive operations to create bespoke service journeys and experiences. Knowledge management also extends to training and development, starting in educational contexts and extending into 
workplaces, which stresses the scope, scale and impacts of effective practices to manage the risks surrounding allergies and intolerances.

Managing such food-related risks extends to the physical servicescape and service process design, which reduces the potential for hazards. This may utilise relatively low costs safety protocols, stronger communication techniques or training to improve staff knowledge. However, the findings also point to the importance of nurturing service cultures where responsiveness and empathy towards affected consumers is embedded in development and performance rewards.

Finally, it is also important to stress to potential to transform absolute risks into opportunity risks in event and foodservice management. Demonstrating robust systems, responsive service and the willingness to create unique experiences for clientele with dietary needs can become a point of market differentiation, creating positive affective bonds and enhancing brand value. Catering for the needs of these segments also provides opportunities to form partnerships and drive innovation as specialist food design and service sub-contractors use their segmentspecific knowledge and resources to create products that can be integrated into event design and operations to reduce risk and generate value.

\section{Limitations and implications for future research}

This study is unique in exploring the subjective, lived experiences of event attendees with allergies, intolerances and coeliac disease. It was limited to a relatively small sample of individuals and adopted an inductive, qualitative data collection and analysis strategy. It also did not systematically differentiate between individuals according to the type or level of health condition, although the differences between these was acknowledged in the sampling, data collection and analysis. The sampling also did not set quotas regarding age, gender or nationality. This limits the scope for generalisation; nevertheless, the findings regarding expectations, the challenges encountered in-situ and consumers' coping practices provide transferable sensitising concepts that can inform subsequent exploratory, evaluative and confirmatory studies of event attendee experiences.

Exploratory studies could use a variety of creative, qualitative elicitation techniques to explore the event experiences of a wider sample of attendees. This includes a more systematic sample of individuals with diverse food sensitivities. Research could try to examine gender differences, and recruit a larger cohort of older respondents, which were underrepresented in the current sample. It could also attempt to sample more systematically people from different countries, which can help to understand how experiences vary according to national contexts. 
Sampling may also distinguish between national and cultural contexts where food sensitivities are more or less widely recognised, or embedded in different legislative regimes. Exploratory studies may also utilise online data generated through social media platforms, examining how experiences are conveyed visually and textually. This type of research can explore how different stakeholders construct, interpret and contest their experiences and agency, examining consumers' psychological and behavioural responses.

Evaluative studies may adopt self-reported surveys to capture and assess experiences and the performance of different operators in meeting consumers' needs. Adopting stratified and quota sampling strategies can help to understand how different consumer segments perceive and respond to different event contexts and service provision strategies or procedures e.g. concerning pre, in-situ and post event marketing communications, food handling, product range, pricing, training and information management. Evaluative studies may also conduct computer-driven sentiment analysis on event-related data generated on social media. Comparative studies across different events and across the different iterations of the same event can be used to monitor trends in consumers' food-related experiences.

Confirmatory studies may extended this work through surveys, or field and lab experiments to identify which service strategies and procedures, and domains of practice (e.g. food choice, information source or signalling technique) result in greater (dis)satisfaction among those with different food sensitivities. There is scope to explore the impacts of food and drink on outcomes for consumers with sensitivities and those without them. Confirmatory research can also assess how performance in specific areas of product development or service delivery (e.g. the use of technology to identify dietary needs and interact with attendees) influences post event attitudes and behaviours.

\section{References}

Armbrecht, J. and Andersson, T. (2020), “The event experience, hedonic and eudaimonic satisfaction and subjective well-being among sport event participants", Journal of Policy Research in Tourism, Leisure and Events, Vol. 12 No. 3, pp. 457-477.

Bascuñán, K., Vespa, M. and Araya, M. (2017), “Celiac disease: Understanding the gluten-free diet”, European Journal of Nutrition, Vol. 56 No. 2, pp. 449-459.

Begen, F., Barnett, J., Payne, R., Gowland, M., DunnGalvin, A. and Lucas, J. (2018), “Eating out with a food allergy in the UK: Change in the eating out practices of consumers with 
food allergy following introduction of allergen information legislation", Clinical and Experimental Allergy, Vol. 48 No. 3, pp. 317-324.

Berners, P. (2019), The Practical Guide to Managing Event Venues, Routledge, Abingdon.

Berridge, G. (2007), Events Design and Experience, Elsevier, Oxford.

Bezzola, T. and Lugosi, P. (2018), "Negotiating place through food and drink: Experiencing home and away", Tourist Studies, Vol. 18 No. 4, pp. 486-506.

Carter, C., Pistiner, M., Wang, J. and Sharma, H. (2020), "Food allergy in restaurants work group report", The Journal of Allergy and Clinical Immunology: In Practice, Vol. 8 No. 1, pp. 70-74.

Crawford, D., Jackson, E. and Godbey, G. (1991), “A hierarchical model of leisure constraints”, Leisure Sciences, Vol. 13 No. 4, pp. 309-320.

Crocker, H., Jenkinson, C. and Peters, M. (2018), "Quality of life in coeliac disease: Item reduction, scale development and psychometric evaluation of the Coeliac Disease Assessment Questionnaire (CDAQ)", Alimentary Pharmacology and Therapeutics, Vol. 48 No. 8, pp. 852-862.

Davies, K. and Jaimangal-Jones, D. (2020), "The case for constructionist, longitudinal and ethnographic approaches to understanding event experiences", Journal of Policy Research in Tourism, Leisure and Events, Vol. 12 No. 3, pp. 323-343.

De Geus, S., Richards, G. and Toepoel, V. (2016), “Conceptualisation and operationalisation of event and festival experiences: Creation of an event experience scale", Scandinavian Journal of Hospitality and Tourism, Vol. 16 No. 3, pp. 274-296.

Endres, A., Endres, R. and Nižić, M. (2021), "Restaurant disclosure of food allergens: Analysis and economic implications", Tourism and Hospitality Research, Vol 21 No 2, pp. 202215.

Foroughi, B., Shah, K., Nikbin, D. and Hyun, S. (2014), “The impact of event quality on fan satisfaction and game attendance in the context of professional soccer in Iran", International Journal of Sports Marketing and Sponsorship, Vol. 15 No. 3, pp.189-205.

Gellweiler, S., Wise, N. and Fletcher, T. (2018), "Understanding the "lived experience" of sport event volunteers: Using the hermeneutic circle as a guiding conceptual framework", Event Management, Vol. 22 No. 4, pp. 629-641.

Getz, D. and Page, S. (2016), Event Studies: Theory, Research and Policy for Planned Events, 3rd ed., Routledge, Abingdon.

Harrison-Walker, L. (2019), "The effect of consumer emotions on outcome behaviors following service failure", Journal of Services Marketing, Vol. 33 No. 3, pp. 285-302. 
Hassanien, A. and Dale, C. (2011), “Toward a typology of events venues", International Journal of Event and Festival Management, Vol. 2 No. 2, pp. 106-116.

Holbrook, M. (2006), “Consumption experience, customer value, and subjective personal introspection: An illustrative photographic essay", Journal of Business Research, Vol. 59 No. 6, pp. 714-725.

Holloway, I., Brown, L. and Shipway, R. (2010), "Meaning not measurement: Using ethnography to bring a deeper understanding to the participant experience of festivals and events", International Journal of Event and Festival Management, Vol. 1 No. 1, pp. 74-85.

Holm, M., Lugosi, P., Croes, R. and Torres, E. (2017) "Risk-tourism, risk-taking and subjective well-being: A review and synthesis", Tourism Management, Vol. 63, pp. 115-122.

Hopkin, P. (2018), Fundamentals of Risk Management: Understanding, Evaluating and Implementing Effective Risk Management, 5th ed, Kogan Page Publishers, London.

IMARC Group (2020), "Food Intolerance Products Market: Global Industry Trends, Share, Size, Growth, Opportunity and Forecast 2020-2025”, IMARC Group, London.

Jackson, C., Vaughan, D. and Brown, L. (2018), "Discovering lived experiences through descriptive phenomenology", International Journal of Contemporary Hospitality Management, Vol. 30 No. 11, pp. 3309-3325.

Jacobsson, L. Hallert, C., Milberg, A. and Friedrichsen, M. (2012), “Coeliac disease-women's experiences in everyday life", Journal of Clinical Nursing, Vol. 21 Nos. 23-24, pp. 3442-3450.

King, J., Kaplan, G. and Godley, J. (2019), "Experiences of coeliac disease in a changing gluten-free landscape”, Journal of Human Nutrition and Dietetics, Vol. 32 No. 1, pp. $72-79$.

Lebwohl, B., Sanders, D. and Green, P. (2018), “Coeliac disease”, The Lancet, Vol. 391 No. 10115, pp. 70-81.

Lee, A. and Newman, J. (2003), "Celiac diet: Its impact on quality of life", Journal of the American Dietetic Association, Vol. 103 No. 11, pp. 1533-1535.

Loh, W. and Tang, M. L. (2018), "The epidemiology of food allergy in the global context", International Journal of Environmental Research and Public Health, Vol. 15 No. 9, 2043

Lomer, M. C. E. (2015), “The aetiology, diagnosis, mechanisms and clinical evidence for food intolerance", Alimentary Pharmacology and Therapeutics, Vol. 41 No. 3, pp. 262-275. 
Lugosi, P., Robinson, R., Golubovskaya, M., Foley, L. and Harwell, J. (2016), “Experiencing parenthood, care and spaces of hospitality", The Sociological Review, Vol. 64 No. 2, pp. 274-293.

Lugosi, P., Golubovskaya, M., Robinson, R., Quinton, S. and Konz, J. (2020a), “Creating family-friendly pub experiences: A composite data study", International Journal of Hospitality Management, Vol. 91, pp. 102690.

Lugosi, P., Robinson, R., Walters, G. and Donaghy, S. (2020b), "Managing experience cocreation practices: Direct and indirect inducement in pop-up food tourism events", Tourism Management Perspectives, Vol. 35, 100702.

MacKenzie, H., Roberts, G., Van Laar, D. and Dean, T. (2010), “Teenagers' experiences of living with food hypersensitivity: A qualitative study", Pediatric Allergy and Immunology, Vol. 21 No. 4p1, pp. 595-602.

McAdams, B., Deng, A. and MacLaurin, T. (2018), "Food allergy knowledge, attitudes, and resources of restaurant employees", British Food Journal, Vol. 120 No. 11, pp. 26812694.

Morgan, M. (2008), "What makes a good festival? Understanding the event experience", Event Management, Vol. 12 No. 2, pp. 81-93.

Nettleton, S., Woods, B., Burrows, R. and Kerr, A. (2009), "Food allergy and food intolerance: Towards a sociological agenda", Health, Vol. 13 No. 6, pp. 647-664.

Olsson, C., Lyon, P., Hörnell, A., Ivarsson, A. and Sydner, Y. (2009), "Food that makes you different: The stigma experienced by adolescents with celiac disease", Qualitative Health Research, Vol. 19 No. 7, pp. 976-984.

Ortolani, C. and Pastorello, E. (2006), "Food allergies and food intolerances" Best Practice and Research Clinical Gastroenterology, Vol. 20 No. 3, pp. 467-483.

Patton, M. (2014), Qualitative Research and Evaluation Methods, 4th edn, Sage, London.

Peniamina, R., Bremer, P., Conner, T. and Mirosa, M. (2014), “The food allergy journey: understanding the lived experiences of food-allergic consumers as a pathway towards improving their wellbeing”, Journal of Research for Consumers, Vol. 25, pp. 20-52.

Putten, M., Frewer, L., Gilissen, L., Gremmen, B., Peijnenburg, A. and Wichers, H. (2006), "Novel foods and food allergies: A review of the issues", Trends in Food Science and Technology, Vol. 17 No. 6, pp. 289-299.

Reic, I. (2017), Events Marketing Management: A Consumer Perspective, Routledge, New York. 
Richards, G. (2020), "Measuring the dimensions of event experiences: Applying the Event Experience Scale to cultural events", Journal of Policy Research in Tourism, Leisure and Events, Vol. 12 No. 3, pp. 422-436.

Robinson, R. and Clifford, C. (2012), “Authenticity and festival foodservice experience", Annals of Tourism Research, Vol. 39 No. 2, pp. 571-600.

Rodriguez-Almagro, J., Hernández Martínez, A., Solano Ruiz, M. and Siles González, J. (2017), "Using mixed-methods research to study the quality of life of coeliac women", Journal of Clinical Nursing, Vol. 26 Nos. 7-8, pp. 1119-1130.

Rust, E. (2020), "Understanding experiential value creation at small-scale events: a multistakeholder perspective", Journal of Policy Research in Tourism, Leisure and Events, Vol. 12 No. 3, pp. 344-362.

Sainsbury, K. and Marques, M. (2018), “The relationship between gluten free diet adherence and depressive symptoms in adults with coeliac disease: A systematic review with metaanalysis", Appetite, Vol. 120, pp. 578-588.

Saldaña, J. (2009), The Coding Manual for Qualitative Researchers, Sage, London.

Schiefert, V. and Matteucci, X. (2018), "Experiences of tourists suffering from food intolerances", Journal of Gastronomy and Tourism, Vol. 3 No. 3, pp. 191-202.

Schoefer, K. and Ennew, C. (2005), “The impact of perceived justice on consumers' emotional responses to service complaint experiences”, Journal of Services Marketing, Vol. 19 No. 5, pp. 261-270.

Shah, S., Akbari, M., Vanga, R., Kelly, C.P., Hansen, J., Theethira, T., Tariq, S., Dennis, M. and Leffler, D.A. (2014), "Patient perception of treatment burden is high in celiac disease compared to other common conditions", The American Journal of Gastroenterology, Vol. 109 No. 9, pp. 1304-1311.

Simpson, S., Lebwohl, B., Lewis, S., Tennyson, C., Sanders, D. and Green, P. (2011), "Awareness of gluten-related disorders: A survey of the general public, chefs and patients", e-SPEN, the European e-Journal of Clinical Nutrition and Metabolism, Vol. 6 No. 5, pp. e227-e231.

Skjerning, H., Hourihane, J., Husby, S. and DunnGalvin, A. (2017), “A comprehensive questionnaire for the assessment of health-related quality of life in coeliac disease (CDQL)", Quality of Life Research, Vol. 26 No. 10, pp. 2831-2850.

Soon, J. (2020), “'Food allergy? Ask before you eat': Current food allergy training and future training needs in food services", Food Control, Vol. 112, 107129. 
Sverker, A., Hensing, G. and Hallert, C. (2005), “'Controlled by food'-lived experiences of coeliac disease", Journal of Human Nutrition and Dietetics, Vol. 18 No. 3, pp. 171-180.

Sverker, A., Östlund, G., Hallert, C. and Hensing, G. (2009), “'I lose all these hours...'Exploring gender and consequences of dilemmas experienced in everyday life with coeliac disease”, Scandinavian Journal of Caring Sciences, Vol. 23 No. 2, pp. 342-352.

Tum, J., Norton, P. and Wright, J.N. (2006), Management of Event Operations, Elsevier, Oxford.

Turnbull, J., Adams, H. and Gorard, D. (2015), “The diagnosis and management of food allergy and food intolerances", Alimentary Pharmacology and Therapeutics, Vol. 41 No. 1, pp. $3-25$.

Wen, H. and Kwon, J. (2019), "Food allergy information sharing and communication strategies in full-service restaurants in the US", Journal of Foodservice Business Research, Vol. 22 No. 1, pp. 50-65.

Wen, H., Park, E., Tao, C., Chae, B., Li, X. and Kwon, J. (2020), "Exploring user-generated content related to dining experiences of consumers with food allergies", International Journal of Hospitality Management, Vol. 85, 102357.

Werner, K., Griese, K.M. and Faatz, A. (2019), "Value co-creation processes at sustainable music festivals: A grounded theory approach", International Journal of Event and Festival Management, Vol. 11 No. 1, pp. 127-144.

Whitaker, J., West, J., Holmes, G. and Logan, R. (2009), "Patient perceptions of the burden of coeliac disease and its treatment in the UK", Alimentary Pharmacology and Therapeutics, Vol. 29 No. 10, pp. 1131-1136.

Zarkadas, M., Dubois, S., MacIsaac, K., Cantin, I., Rashid, M., Roberts, K. C., La Vieille, S., Godefroy, S. and Pulido, O. (2013), "Living with coeliac disease and a gluten-free diet: A Canadian perspective", Journal of Human Nutrition and Dietetics, Vol. 26 No. 1, pp. $10-23$.

Ziakas, V. and Boukas, N. (2013), "Extracting meanings of event tourist experiences: A phenomenological exploration of Limassol carnival", Journal of Destination Marketing and Management, Vol. 2 No. 2, pp. 94-107.

Ziakas, V. and Boukas, N. (2014), “Contextualizing phenomenology in event management research", International Journal of Event and Festival Management Vol. 5 No. 1, pp. $56-73$. 